\title{
Crystallization of $M$-type hexagonal ferrites from mechanically activated mixtures of barium carbonate and goethite
}

\author{
J TEMUUJIN $*, \dagger$, M AOYAMA ${ }^{\dagger}$, M SENNA ${ }^{\dagger}$, T MASUKO ${ }^{\dagger \dagger}$, C ANDO ${ }^{\dagger \dagger}$, H KISHI $^{\dagger \dagger}$ and \\ A MINJIGMAA \\ *Institute of Chemistry and Chemical Technology, Mongolian Academy of Sciences, Ulaanbaatar 51, Mongolia \\ ${ }^{\dagger}$ Department of Applied Chemistry, Faculty of Science and Technology, Keio University, 3-14-1 Hiyoshi, \\ Yokohama 223-8522, Japan \\ ${ }^{\dagger \dagger}$ Materials Research and Development Division, General Research and Development Laboratories, Taiyo Yuden \\ Co. Ltd., 5607-2 Nakamuroda, Gunma 370-3347, Japan
}

MS received 16 May 2006

\begin{abstract}
M$-type hexagonal ferrite precursor was prepared by a soft mechanochemical treatment of $\mathrm{BaCO}_{3}$ and $\alpha$-FeOOH mixtures. The effect of milling on its structure and thermal behaviour was examined by XRD, SEM and FTIR. Well crystallized $M$-type hexagonal ferrite was formed from just $1 \mathrm{~h}$ milled precursors at $800^{\circ} \mathrm{C}$. The beneficial effect of milling was explained in terms of increased homogeneity with simultaneous hetero bridging bond formation between powder constituents.
\end{abstract}

Keywords. $\quad M$-type hexagonal ferrite; mechanical activation; powder; crystallization.

\section{Introduction}

Hexagonal ferrite, $\mathrm{BaFe}_{12} \mathrm{O}_{19}$ ( $M$-phase), is widely studied as a permanent magnet and more recently for high-density magnetic recording media. Many synthesis techniques, such as solid state reaction (Steier et al 1999), co-precipitation (Ogasawara and Oliveira 2000; Janasi et al 2002), combustion (Huang et al 2003), have been exploited. Mechanochemical method is one of the interesting methods for the preparation of $M$-phase. There are several reports on this subject (Subrt and Tlaskal 1993; Ding et al 1998; Liu et al 2000; Mendoza-Suarez et al 2001). From mechanically activated mixtures, crystallization of $M$-phase usually occurs between 800 and $1200^{\circ} \mathrm{C}$ and shows nano or submicron size. However, mechanical milling is a high energy consuming process, which requires additional equipment such as high energy shaker mill (Ding et al 1998; Liu et al 2000).

Subrt and Tlaskal (1993) have described that if starting mixture contains hydroxyl containing compounds the crystallization of $M$-phase occurs at $800^{\circ} \mathrm{C}$. They have attributed this reaction to the appearance of a highly reactive iron oxide formed during dehydration of iron hydroxides.

We have previously reported that a soft-mechanochemical reaction has a great potential for the synthesis of hexagonal ferrites such as $Y$-phase $\left(\mathrm{Ba}_{2} \mathrm{Co}_{2} \mathrm{Fe}_{12} \mathrm{O}_{22}\right)(\mathrm{Te}$ -

*Author for correspondence (jtemuujin@yahoo.com) muujin et al 2004). We found that the existence of the hydroxyl containing compounds in the raw materials does not guarantee an improved solid state reaction rate of the powder constituents. Soft-mechanochemical reaction takes place during the milling of water or hydroxyl containing compounds because of their easy polarization of the surface hydroxyl groups and allows obtaining of precursors containing hetero bridging bonds between the metallic species by relatively mild mechanical stresses. The aim of the present research is to characterize the reaction mixture of the mechanically treated hydroxyl containing compounds and to evaluate its crystallization behaviour during heat treatment.

\section{Experimental}

The starting reagents were goethite $\alpha-\mathrm{FeOOH}$ (GNA-85N, with $0.2 \mu \mathrm{m}$ long needle like morphology) from Toda Kogyo Corp. and $\mathrm{BaCO}_{3}(0.2 \mu \mathrm{m}$ long rod like morpho$\operatorname{logy}$ ), both with analytical grade purity. A stoichiometric mixture for $M$-phase was activated with multi-ring type mill, Mechano Micros ${ }^{\circledR}$ (Nara Machinery) for 1 and $4 \mathrm{~h}$. The rates of revolution and counter-revolution of the rotor and the vessel were fixed at 1250 and $250 \mathrm{~min}^{-1}$, respectively. A $30 \mathrm{~g}$ of the powder, corresponding to $15 \%$ of the effective volume of the vessel, was charged for activation. After milling, samples were calcined at 600,800 and $1000^{\circ} \mathrm{C}$ in air.

Samples were characterized by a powder X-ray diffractometry (Rigaku RINT 2000), FTIR (Bio-Rad Win-IR) and FE-SEM (Hitachi S-4000). 


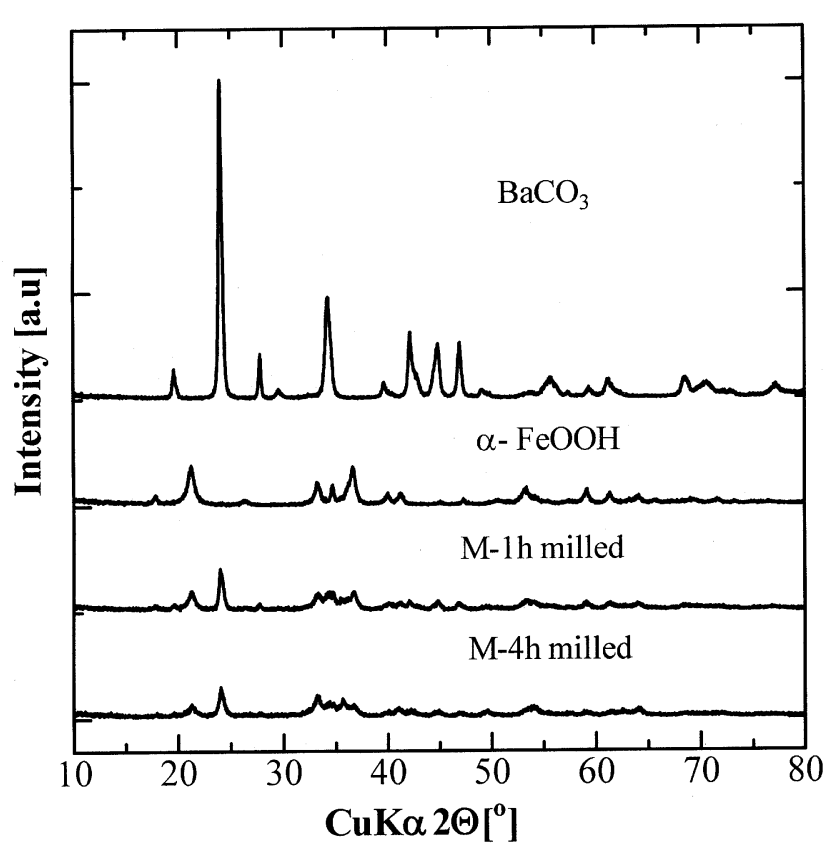

Figure 1. XRD patterns of the raw materials and the mixture $(M-)$ milled for 1 and $4 \mathrm{~h}$.
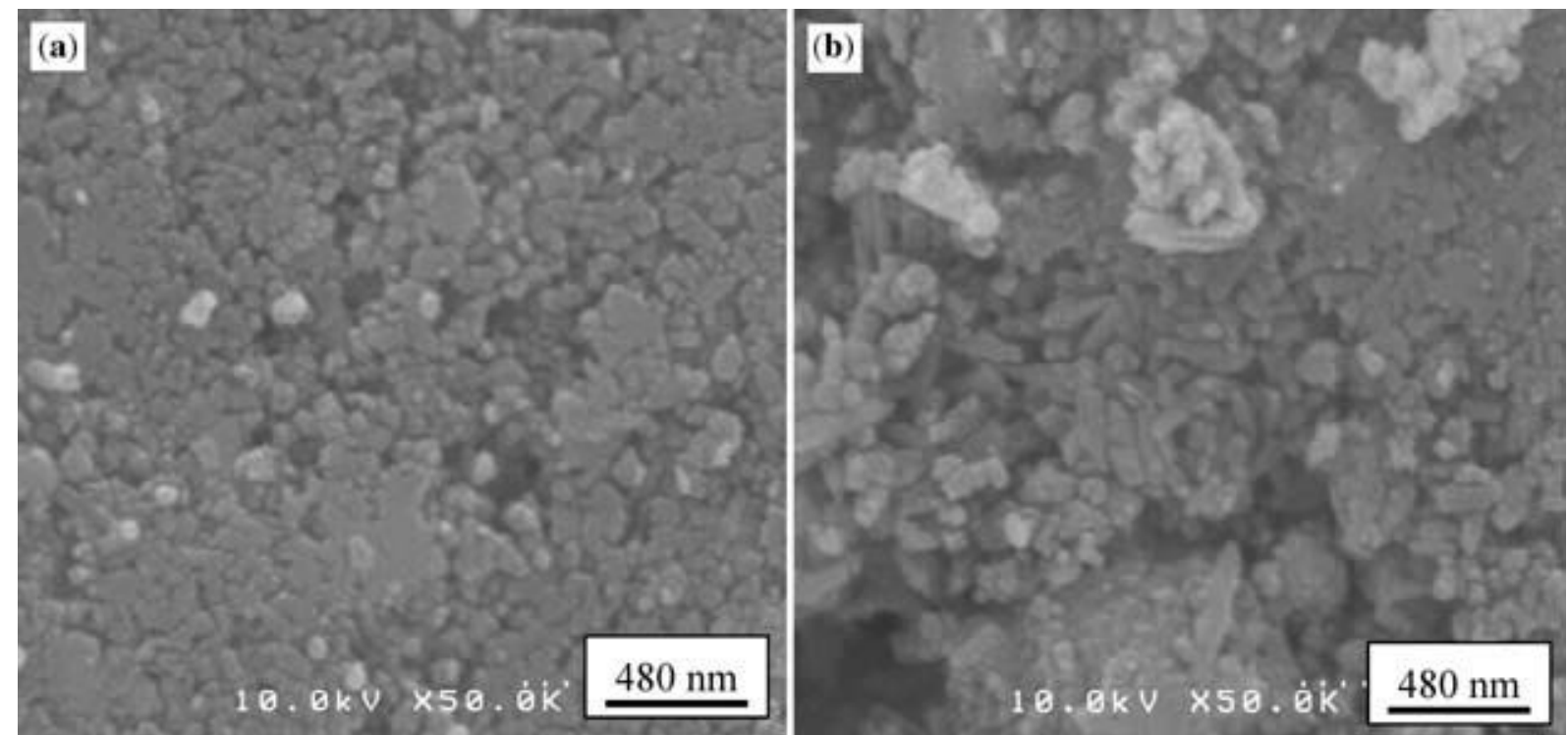

Figure 3. FE-SEM micrographs of the samples milled for $1 \mathrm{~h} \mathrm{(a)}$ and $4 \mathrm{~h}(\mathbf{b})$.

\section{Results and discussion}

The XRD patterns of the raw materials and samples milled for 1 and $4 \mathrm{~h}$ are shown in figure 1. Milling significantly reduced diffraction intensities of barium carbonate and goethite peaks. However, the mixture was not fully amorphized even after $4 \mathrm{~h}$ milling. There is a small change in terms of diffraction intensity between the samples milled for 1 and $4 \mathrm{~h}$. Diffraction line broadening of the milled

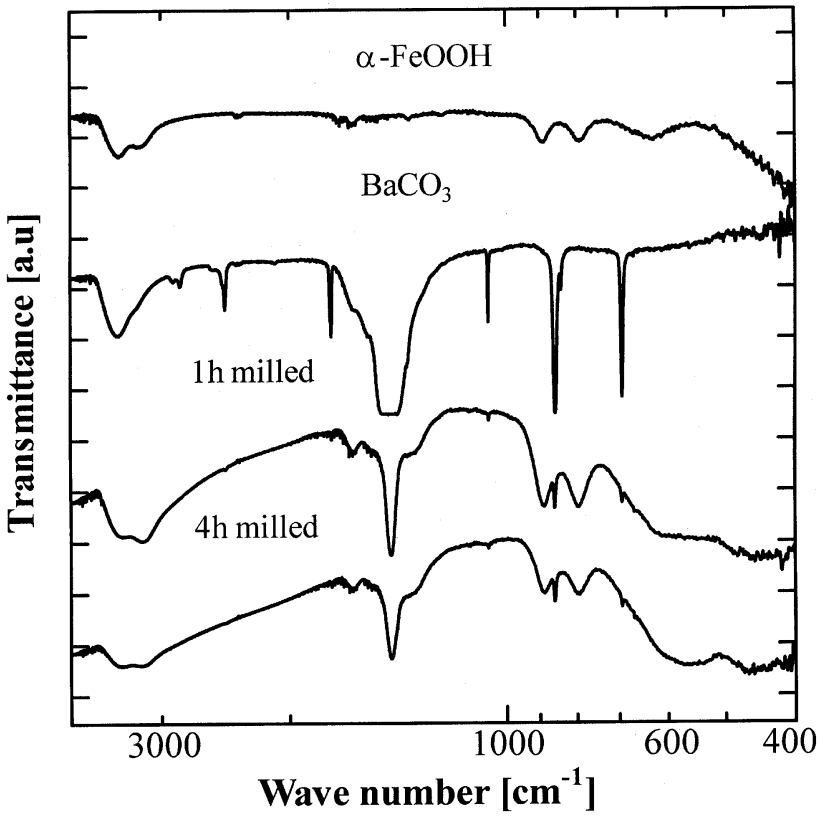

Figure 2. FTIR spectra of the raw materials and the mixture $(M-)$ milled for 1 and $4 \mathrm{~h}$. 
due to $\mathrm{OH}$ and $\mathrm{H}_{2} \mathrm{O}$ vibrations and a band at $630 \mathrm{~cm}^{-1}$ due to lattice vibration of $\mathrm{FeO}_{6}$ octahedra as reported previously (Temuujin et al 2004). Most of these bands are present in the milled samples. However, a stretching vibration of the raw goethite, $\mathrm{v}\left(\mathrm{FeO}_{6}\right)$, appearing at $630 \mathrm{~cm}^{-1}$ became flat by milling for $1 \mathrm{~h}$ and broader and centred at $565 \mathrm{~cm}^{-1}$ after milling for $4 \mathrm{~h}$. Similar changes also occurred in the milled $Y$-phase hexaferrite composition and we have attributed it to substitution of Co cations into octahedral lattice of goethite or partial decomposition of goethite into hematite like structure (Temuujin et al 2004). However, $M$-phase hexaferrite does not have Co atoms in its structure. Therefore, the above mentioned change of $v\left(\mathrm{FeO}_{6}\right)$ vibration is probably related with an appearance of the hematite like structure. Weakening of the carbonate bands of the $\mathrm{BaCO}_{3}$ and appearance of the hematite like structure may also indicate a chemical bond formation between iron and barium constituents with partial decarbonation.

Scanning electron micrographs of the samples milled for 1 and $4 \mathrm{~h}$ are shown in figure 3 . The sample milled for $1 \mathrm{~h}$ comprises spherical particles with their average particle size between 50 and $60 \mathrm{~nm}$, indicating improved homogeneity and particle size reduction of the starting powders. Increasing the milling time causes some agglomeration with change of morphology from spherical to rod like.

Figure 4 shows XRD patterns of the milled samples after calcining at different temperatures. Both samples calcined at $600^{\circ} \mathrm{C}$ contain $\mathrm{BaFe}_{2} \mathrm{O}_{4}$ and $\alpha-\mathrm{Fe}_{2} \mathrm{O}_{3}$ phases. Solid state reaction for the formation of barium hexaferrite from hematite and barium carbonate usually occurs via 2 steps (Schoeps 1979)

$$
\begin{aligned}
& \mathrm{BaCO}_{3}+\mathrm{Fe}_{2} \mathrm{O}_{3} \rightarrow \mathrm{BaFe}_{2} \mathrm{O}_{4}+\mathrm{CO}_{2}, \\
& \mathrm{BaFe}_{2} \mathrm{O}_{4}+5 \mathrm{Fe}_{2} \mathrm{O}_{3} \rightarrow \mathrm{BaO} \cdot 6 \mathrm{Fe}_{2} \mathrm{O}_{3} .
\end{aligned}
$$

The first reaction starts between 600 and $750^{\circ} \mathrm{C}$ and the second between 720 and $900^{\circ} \mathrm{C}$ (Schoeps 1979). Completion of the overall reaction takes place at about $1000-1100^{\circ} \mathrm{C}$ (Schoeps 1979; Steier et al 1999). Therefore, we can suggest that mechanical activation drastically improved the rate of solid state reaction to form barium hexaferrite and the first step was completed at below $600^{\circ} \mathrm{C}$. In the present case, the overall reaction was completed at $800^{\circ} \mathrm{C}$ without any other intermediates. Just $1 \mathrm{~h}$ milling was sufficient to cause formation of barium hexaferrite at $800^{\circ} \mathrm{C}$. An increase

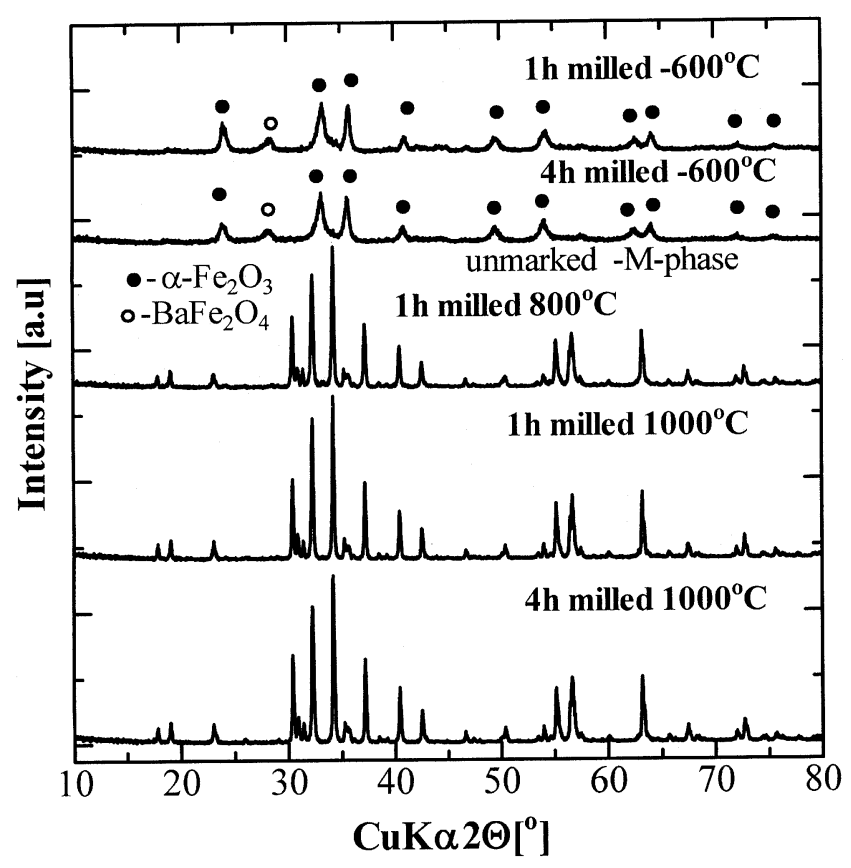

Figure 4. XRD patterns of the milled samples after calcining at different temperatures.
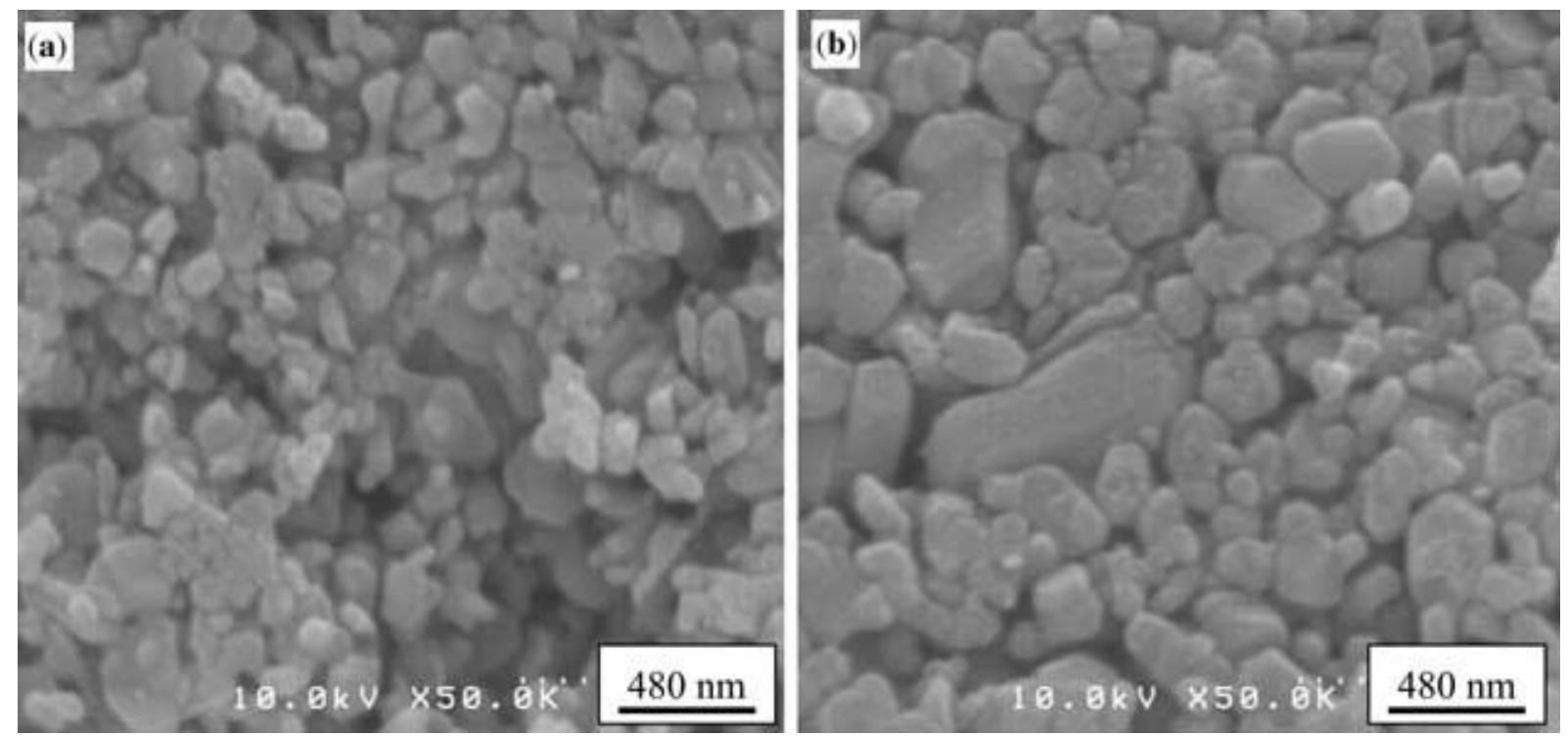

Figure 5. FE-SEM micrographs of the $1 \mathrm{~h}$ milled sample after calcining at 800 (a) and $1000^{\circ} \mathrm{C}(\mathbf{b})$. 
in the milling time or calcination temperature does not exhibit any considerable effect on the crystallization behaviour of the $M$-phase. As discussed above, the mechanical activation results in homogenization and possible hetero bridging bond formation between powder constituents during milling and that could be the reason of the improved solid state reactivity.

In the micrograph shown in figure 5 for $1 \mathrm{~h}$ milled sample (a), we observe that the barium hexaferrite obtained by calcining at $800^{\circ} \mathrm{C}$ consists of fine hexagonal particles of about $50-100 \mathrm{~nm}$. By increasing the calcination temperature, sample (b) causes negative consequences, i.e. increasing the average particle size with some abnormal grain growth.

\section{Conclusions}

Phase pure $M$-phase hexaferrite was synthesized from the mixtures prepared from goethite and barium carbonate by using multi-ring type mill, and subsequently calcining at $800^{\circ} \mathrm{C}$. Milling for just $1 \mathrm{~h}$ caused similar structural changes with $4 \mathrm{~h}$ milled sample. The main reason of the improved solid state reaction rate of the milled mixture is associated with the reduction of the particle size in the starting mixture and simultaneous formation of the hetero bridging bonds toward the products among the dissimilar reaction constituents.

\section{Acknowledgement}

This research was partially supported by the Ministry of Agriculture and Science and Technological Foundation of Mongolia under the project "Technological investigation on the preparation of the ecologically pure activated phosphorous fertilizer from natural phosphate rock".

\section{References}

Ding J, Tsuzuki T and McCormick P G 1998 J. Magn. Magn. Mater. 177-181931

Janasi S R, Emura M, Landgraf F J G and Rodrigues D $2002 \mathrm{~J}$. Magn. Magn. Mater. 238168

Huang J, Zhuang H and Li W 2003 J. Magn. Magn. Mater. 256390

Liu X, Wang J, Ding J, Chen M S and Shen Z X 2000 J. Mater. Chem. 101745

Mendoza-Suarez G, Matutes-Aquino J A, Escalante-Garcia J I, Mancha-Molinar H, Rios-Jara D and Johal K K $2001 \mathrm{~J}$. Magn. Magn. Mater. 22355

Ogasawara T and Oliveira M A S 2000 J. Magn. Magn. Mater. 217147

Schoeps W 1979 Silikattechnik 30195

Steier H P, Requena J and Moya J S 1999 J. Mater. Res. 14 3647

Subrt J and Tlaskal J 1993 Solid State Ionics 63-65 110

Temuujin J, Aoyama M, Senna M, Masuko M, Ando T and Kishi H 2004 J. Solid State Chem. 1773903 